\title{
Assessment of Insertion Torque of Mini-implant and Its Correlation with Primary Stability and Pain Levels in Orthodontic Patients
}

\author{
Swapna Sreenivasagan ${ }^{1}$, Aravind Kumar Subramanian², Nivethigaa B $^{3}$
}

\begin{abstract}
Aim: The aim of this study was to assess the insertion torque of the mini-implant used in orthodontic patients and to assess the correlation between the insertion torque, primary stability, and perception of pain in patients undergoing orthodontic therapy with mini-implant-augmented anchorage.

Material and methods: Among the patients undergoing orthodontic therapy, 31 samples who required mini-implant for anchorage purpose were selected. A total of 59 mini-implants were placed in these patients. This included interradicular mini-implants and extra-alveolar miniscrews. Immediately after placement, the insertion torque in all these was measured using a digital torque meter and primary stability was assessed by identifying any mobility of the implant placed. Primary stability was noted at two time intervals immediate post-placement and 1 week after that. All the mini-implants that were considered in this study were immediately loaded. Patients were asked to record any pain experienced on the visual analog scale (VAS) score sheet at 24 hours and 1 week post-placement.

Results: Among the mini-implants placed, those with $2 \mathrm{~mm}$ diameter needed higher placement torque, i.e., infrazygomatic crest mini-implants and buccal shelf mini-implants were placed with average placement torque of 10.08 and $10.25 \mathrm{~N} \mathrm{~cm}$, respectively. Extra-alveolar screws caused more pain, especially higher in the mandible than the maxilla. Decrease in pain scores was noted from $\mathrm{T}_{0}$ to $\mathrm{T}_{1}$ in almost all the cases.

Conclusion:Thicker mini-implant needed more insertion torque and highest insertion torque was recorded with extra-alveolar screws. No direct correlation could be obtained with the pain levels experienced by the patients and with the primary stability of the mini-implants.

Clinical significance: Mini-implants placed with an insertion torque above the recommended range tend to fail and break more often. Patients placed with extra-alveolar bone screws reported more pain than that of the smaller-dimension mini-implant.

Keywords: Anchorage, Insertion torque, Mini-implants, Primary stability, Visual analog scale score.

The Journal of Contemporary Dental Practice (2021): 10.5005/jp-journals-10024-2969
\end{abstract}

\section{INTRODUCTION}

The interface characteristic between the implant and bone can be expressed in relation to the implant placement torque (IPT) when tightening the mini-implant into the bone. ${ }^{1}$ In order for a mini-implant to be stable, the mechanical locking (torque) of the screw in the bone must be able to withstand the applied force. ${ }^{2}$ It is important to estimate the torque at which strain remains physiological and provides stability for the mini-implants. Initial stability is what results from mechanical engagement of the miniimplant with cortical bone immediately after placement.,

The primary stability of the mini-implant is important because most incidences of orthodontic mini-screw failure occur during the early stage. ${ }^{5,6}$ Insertion torque (IT) is defined as the amount of torque required to overcome the frictional force between the screw and the bone during insertion procedures. The recommended range of IT is $5-10 \mathrm{~N} \mathrm{~cm}$, which is associated with higher success rates of orthodontic mini-implants. ${ }^{7}$ Increased IT induces overcompression of the bone tissue whereas an insufficient IT will prevent ideal drilling of mini-implant into the bone. ${ }^{8}$ Both these will result in inadequate primary stability and cause implant failures.

The IT also varies according to the location, the type, and dimension of the mini-implants. Due to the variations in various regions of the bone among individuals, the site of insertion should always be evaluated on an individual basis. The cortical bone thickness of optimal insertion sites of the areas where there is thicker
${ }^{1-3}$ Department of Orthodontics, Saveetha Dental College and Hospital Saveetha Institute of Medical and Technical Sciences, Saveetha University, Chennai, Tamil Nadu, India

Corresponding Author: Aravind Kumar Subramanian, Department of Orthodontics, Saveetha Dental College and Hospital, Saveetha Institute of Medical and Technical Sciences, Saveetha University, Chennai, Tamil Nadu, India, Phone: +9198412 99939, e-mail: aravindkumar@ saveetha.com

How to cite this article: Sreenivasagan S, Subramanian AK, B Nivethigaa. Assessment of Insertion Torque of Mini-implant and Its Correlation with Primary Stability and Pain Levels in Orthodontic Patients. J Contemp Dent Pract 2021;22(1):84-88.

Source of support: Nil

Conflict of interest: None

cortical bone predrilling might be recommended in order to avoid a higher IT and failure. ${ }^{9}$ The alveolar bone density of the buccal cortical region of the mandible was statistically higher than in the maxilla, except between central and lateral incisors. ${ }^{5}$

Mini-implants can be placed either by predrilling or by the self-drilling method. The predrilling helps reduce the IT required. The self-drilling method has been adopted worldwide because placement of self-drilling screws requires shorter operating time and also cause less bone debris and thermal damage, and is associated with less morbidity and minimal patient discomfort. ${ }^{10}$ 
The main objective of this study was to assess the ITs of the mini-implants placed, to evaluate the IT needed for interradicular mini-implant in the maxilla and mandible, to evaluate the IT for extraalveolar mini-screws, to evaluate if there is any correlation between different insertion sites and the IT, to assess if there is any correlation between the IT and the primary stability of the miniimplants, and also grade the amount of pain experienced by the patient. For the mini-implants that failed during the course of the study, the reason for failure was evaluated and assessed if it can be correlated to the IT during placement.

\section{Materials and Methods}

The study is a prospective controlled clinical trial and was conducted in the Department of Orthodontics, Saveetha Dental College. The study was approved by the institutional review board; the approval number is SRB/SDC/ORTHO-1804/20/01. At the power of $90 \%$, the sample size was estimated to be 40 . Patients undergoing orthodontic treatment who require mini-implants and mini-screws for anchorage augmentation, good periodontal health with adequate bone support, good oral hygiene, and no smoking habit were included in the study. Patients with systemic disorders such as diabetes, blood pressure, or any kind of cardiac disorder; patients with periodontal compromise and poor oral hygiene; and patients with smoking habit, improper bone support, inadequate width of attached gingiva, and poor oral hygiene were excluded from the study. Total 31 orthodontic patients who required skeletal anchorage reinforcement were chosen. An informed consent was obtained for the same. The mean age of the patients was $27 \pm 9$ years that included 15 males and 16 females. A total of 59 miniimplants were placed in these patients.

Extra-alveolar bone screws used were the Favanchor TM Skeletal anchorage system (India) and interradicular mini-screws were from SK Surgicals (Pune, India). The infrazygomatic crest and buccal shelf screws that were placed were of the dimensions $2 \times$ $12 \mathrm{~mm}$. The interradicular mini-implants were of 1.3 and $1.5 \mathrm{~mm}$ stainless steel. A total of 12 infrazygomatic mini-implants were placed in six patients out of which four were females and two were males. Buccal shelf mini-implants were placed in adult patients with class III malocclusion. A total of 32 interradicular mini-implants were placed in the maxilla, 13 of them were in the right side and 19 of them were placed in the left side; 11 interradicular mini-implants were placed in the mandible out of which 4 were in the right side 7 were in the left side. Study characteristics and descriptions are mentioned in Table 1.

The site of mini-implant insertion was preassessed with an intraoral periapical radiograph to visualize the interradicular distance available for insertion. All the mini-implants that were placed were self-drilling and were placed using their specific driver provided by the manufacturer. All the mini-implants that were placed in a fashion such that all the threads of the mini-implant were inside the bone and only the neck portion of the mini-implant was visible outside. Mini-implants in the study were placed by the single operator. Post-placement assessment was done with the intraoral periapical radiograph for interradicular mini-implants and the posteroanterior (PA) cephalogram for extraalveolar mini-screws.

For torque measurement, a Lutron Make Digital Torque meter TQ-8800 (Fig. 1) was used. The torque meter had a capacity of measuring up to $15 \mathrm{~kg} \mathrm{~cm}$ and was provided with a separate probe and had the display to record the data in $\mathrm{kg} \mathrm{cm}$ and $\mathrm{N} \mathrm{cm}$. The size of the instrument was $180 \times 72 \times 32 \mathrm{~mm}$. Twenty-four hours later,
Table 1: Distribution of mini-implants based on site of implant placement, gender, and site of failure

\begin{tabular}{|c|c|c|c|c|}
\hline \multirow[b]{2}{*}{ Characteristics } & \multirow{2}{*}{$\begin{array}{l}\text { Infrazygomatic } \\
\text { crest mini- } \\
\text { screws }\end{array}$} & \multirow{2}{*}{$\begin{array}{l}\text { Buccal shelf } \\
\text { mini-screws }\end{array}$} & \multicolumn{2}{|c|}{$\begin{array}{l}\text { Interradicular } \\
\text { mini-implants }\end{array}$} \\
\hline & & & Maxilla & Mandible \\
\hline \multicolumn{5}{|c|}{ Based on gender } \\
\hline Male & 2 & 2 & 8 & 6 \\
\hline Female & 4 & 0 & 14 & 5 \\
\hline \multicolumn{5}{|c|}{ Based on the side } \\
\hline Total & 12 & 4 & 32 & 11 \\
\hline Right & 6 & 2 & 13 & 4 \\
\hline Left & 6 & 2 & 19 & 7 \\
\hline \multicolumn{5}{|c|}{ Based on site of failure } \\
\hline Right & 1 & 0 & 2 & 0 \\
\hline Left & 0 & 0 & 2 & 0 \\
\hline
\end{tabular}

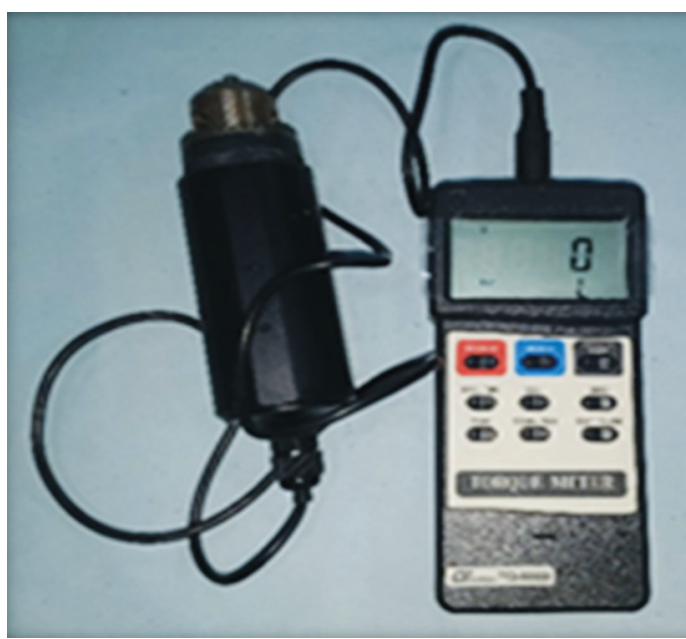

Fig. 1: Image representing the Lutron Make Digital Torque meter TQ8800 used to record the IT during mini-implant placement

the patients were recalled and the pain was graded with the visual analog scale (VAS). The primary stability was assessed using a cotton tweezer to see if there is any kind of mobility. ${ }^{10,11}$

All the mini-implants that were placed in this study were immediately loaded with a standardized force of $400 \mathrm{~g}$ per side for extraalveolar mini-implants and $250 \mathrm{~g}$ for the interradicular mini-implants. The patients were provided with a prescription of pain medications, which was a combination of aceclofenac and paracetamol and told to consume only if required and after informing the physician. The patient was asked to report for review 7 days after placement, which was recorded as $T_{1}$, and in this review the stability of the placed implant was assessed as well as the patient was asked to grade on the VAS score to assess if they had any pain in the site where the mini-implants were placed. The assessment of pain score and mobility was done at $\mathrm{T}_{0}$ and $\mathrm{T}_{1}$.

\section{Statistical Analysis}

The data were collected and tabulation was done. The statistical analysis was carried out using IBM SPSS statistics (version 20). Descriptive statistics was done to assess the IT and pain score among the three implant groups and Pearson's correlation was done to assess the correlation between the IT and pain score at two intervals. 
Table 2: Correlation between placement torque and pain scores at $\mathrm{T}_{0}$ and $\mathrm{T}_{1}$

\begin{tabular}{lllllll}
\hline Type of implants & & Pearson's & & Pearson's \\
correlation & Sig. \\
\hline Infrazygomatic crestal implants & 10.06 & 8.9 & 0.22 & 0.5 & 3.9 & -0.072 \\
Buccal shelf implants & 10.25 & 9.5 & 0.3 & 0 & 5.25 & 0.8 \\
Interradicular implants & 6.6 & 4.7 & 0.57 & 0 & 1.7 & 0.1 \\
\hline
\end{tabular}

Table 3: Failure of mini-implant and causation

\begin{tabular}{lllll}
\hline Type of mini-implant & Maxilla/mandible & Side & Cause of failure & IT \\
\hline IZC & Maxilla & Right & Food accumulation & 7 \\
Interradicular & Mandible & Right & Nerve injury & 5 \\
Interradicular & Maxilla & Left & Root contact & 13 \\
Interradicular & Maxilla & Right & Implant breakage during insertion & Couldn't assess \\
Interradicular & Mandible & Left & Implant breakage during insertion & Couldn't assess \\
Interradicular & Mandible & Right & Implant breakage during insertion & Couldn't assess \\
Interradicular & Maxilla & Right & Implant breakage during insertion & Couldn't assess \\
IZC & Maxilla & Left & Soft tissue coverage and mobile & 6 \\
Interradicular & Maxilla & Right & Mobile & 11 \\
\hline
\end{tabular}

\section{Results}

Comparing the intra-alveolar implants and extraalveolar screws, the IT and pain were found to be higher with IZC implants and buccal shelf mini-screws. Of all, buccal shelf mini screws had the highest IT of $10.25 \mathrm{~N} \mathrm{~cm}$. On assessing the correlation between the VAS score $\left(T_{0}, T_{1}\right)$ and maximum IT, mild positive correlation was noted. Extraalveolar screws caused more pain, especially in the mandible than in the maxilla. Pain score at $T_{1}$ was found to be reduced to baseline values in almost all the cases of interradicular mini-implants. The average IT of interradicular mini-implants is 6.6 $\mathrm{N} \mathrm{cm}$ and the extraalveolar mini-implant with an average IT of 10 $\mathrm{N} \mathrm{cm}$. Patients for whom infrazygomatic mini-implants and buccal shelf mini-implants were placed experienced more pain, which was reported as almost unbearable during the initial evaluation done within 24 hours after placement of the mini-implant. The pain levels were lower in the interradicular mini-implant and some patients even said they had no pain in the follow-up after 7 days (Table 2).

Table 3 shows the characteristics of the failed mini-implants and the causation. Out of the 59 implants considered in the study, failure was noted with 9 implants. The extraalveolar screws also required a higher IT and more deflection of the cheeks and buccal mucosa during placement; these regions are also prone to problems of more food accumulation and soft tissue entrapment.

\section{Discussion}

Mini-implants have become an essential component that provides resistance to any unwanted tooth movement during orthodontic treatment. $^{12,13}$ In our study, frequent need for mini-implants was noted in the maxilla than in the mandible. This is in accordance with studies that show mini-implant-supported anchorage is often used in the maxilla as noted by Jain et al. ${ }^{14}$ Among the extraalveolar screws, infrazygomatic mini-implants were most commonly placed when compared to buccal shelf implants. ${ }^{15}$ Buccal shelf miniimplants placed in class III patients were mostly for the purpose of camouflage. ${ }^{16,17}$ Interradicular mini-implants are often used in extraction cases for retraction with the use of coil springs and e-chain. ${ }^{18,19}$ In our dental outpatient setting, the female to male ratio was comparatively higher indicating the increased concern for esthetics among the female. This was also observed in previous studies where more of female patients underwent extraction and orthodontic correction of malocclusion with mini-implant for retraction or extraalveolar mini-screws for camouflage. ${ }^{20-22}$

A thorough knowledge about the acceptable IT at any location is needed during placement of mini-implant, which will allow the orthodontist to place them with the utmost care to achieve a maximum primary stability. A nontraumatic precise procedure during insertion would provide a better patient compliance and reduce the side effects such as inflammation and pain. From the findings of this study, it is evident that interradicular mini-implant required lower IT in comparison to the extraalveolar mini-screws. Mini-implants placed with a higher IT than the recommended values experienced more failure in comparison to those that had average placement torque. An average IT in interradicular miniimplant and extraalveolar mini-screws were noted to be 6.6 and $10 \mathrm{~N} \mathrm{~cm}$, respectively. Different densities in the bone can be noted in different areas such as the maxilla posterior, which has about 1-2 mm of cortical bone and the mandibular posterior region has a higher cortical bone and density than the maxillary posterior. ${ }^{23}$ High torque values noted in this study with the extraalveolar screws can be attributed to the difference in the cortical bone thickness in these regions. These findings in our study were almost similar to the average observed in Reyenders et al. and Miyawaki et al. where they require a higher IT for the regions that have a thicker cortical bone to penetrate through. ${ }^{3,24,25}$

The extra-alveolar mini-implants were placed with average placement torque of $10.08 \mathrm{~N} \mathrm{~cm}$ for IZC mini-implants and 10.25 $\mathrm{N} \mathrm{cm}$ for buccal shelf mini-implants. Highest pain scores of 9.5 and 8.9 on VAS at $\mathrm{T}_{0}$ were recorded when buccal shelf mini-implants with an IT of 10.25 and a VAS score of 8.9 when infrazygomatic crest mini-implants were placed with an average IT of 10.06 . Mild positive correlation was observed between the IT and initial VAS scores recorded; this correlation was statistically significant for buccal shelf mini-implants and interradicular mini-implants. The pain scores were higher for the mini-implants placed in the extraalveolar region. 
In the present study, out of 59 mini-implants, 9 experienced failure during the course of the study. Three mini-implants failed due to poor oral hygiene, one due to nerve injury that occurred during placement, and one due to root contact. Careful meticulous planning with pretreatment radiographs as an adjuvant can help in overcoming these placement issues. Mobile implants noted during the course of the study were left in place and reassessed for healing to aid in further continuation of treatment. Complications such as soft tissue coverage over the implant surface were treated by soft tissue relief. Among the mini-implants used, breakage occurred with four interradicular implants and hence the IT couldn't be assessed. Various reasons that can be attributed to this breakage include increased torque, quality of the bone screw, angulation of placement, practitioner skill, or bone density.

Inadequate primary stability can result in loosening of the implant during the course of treatment. ${ }^{26}$ Assessment of miniimplant stability is always a challenge to do clinically. The main factor that influences primary stability based on the patient are the bone quality whereas implant insertion-related factors include the type of implant placed, the angulation at which it is placed, depth of insertion, and the IT. ${ }^{24,27,28}$ Optimal IT is necessary to achieve good primary stability as an excessive torque can lead to fractures in the cortical bone and bone resorption, hence to failure of the mini-screw. Increased ITs may lead to higher failure rates caused by excessive bone compression. ${ }^{29}$ Tepedino et al. suggested that when mini-implants are placed with excessive torque, then there can be fractures in the cortical portion of the bone and bone resorption, hence to failure of the mini-screw. ${ }^{30}$ For the insertion of a miniimplant in the region of a thick cortical bone, microcracks or heat damage can be side effects and will lead to bone resorption, which leads to a failure of the screw. ${ }^{31,32}$ Mini-implants to be placed in an area where the gingiva is thin in order to achieve primary stability and prevent excessive tipping. ${ }^{33}$

The mini-screws with the greater diameter and deeper threads need a greater IT to obtain better stability. ${ }^{34,35}$ Severe angulation during insertion may create slippage of the mini-implant at its first contact with bone. The incidence of mini-implants contacting the root contact when placing the mini-implants especially in the interradicular sites increases the chance of the mini-implant failing. ${ }^{23}$ In our study, one interradicular implant failed due to root contact. ${ }^{33}$ Comparing self-drilling and predrilling implants, the former offers a better stability in orthodontic patients where immediate loading is done. ${ }^{36}$ In predrilled implants, the appropriate ratio between implant and predrilling diameter is also crucial to aid in stability.

In orthodontics, the benefit of the treatment outcome is obtained after a period of patience and the patient experiences mild to moderate pain during the course of the treatment. ${ }^{37}$ For the placement of mini-implant, topical or local anesthesia is required. ${ }^{38}$ As noted by Valieri et al., most patients have an unpleasant sensation during and after placement and felt pressure during placement. ${ }^{39}$ Patients tend to overestimate the pain associated with the placement and procedure of mini-implants during orthodontics. ${ }^{40} \mathrm{Kim}$ et al. noted that the most negative impact in mini-implant placement is pain and discomfort during placement followed by difficulty with cleaning. ${ }^{41}$ In this study, all the patients who were placed with mini-implants invariably reported with some pain; that later subsided in the 1 week follow-up.

The achieved success rate of mini-implant was $87.5 \%$ in studies done by Motoyoshi et al. ${ }^{12}$ There are various limitations of this short-term study that include it not having equal samples in each type of mini-implant and unequal number of male and female participants. In future, a well-designed randomized controlled trial can be conducted to determine the association between the IT in comparison to the primary stability of the mini-implant and the failure and complications that arose; also post-placement stability can be done over a period of time and be assessed with a periotest for more efficient understanding with the correlation between torque during placement and the stability.

\section{Conclusion}

Thicker mini-implant needed more IT. Highest IT was recorded with extraalveolar screws. Mini-implants placed with an IT above the recommended range tend to fail and break more often. Patients placed with extraalveolar bone screws reported more pain than that of the smaller-dimension mini-implant. No direct correlation could be obtained with the pain levels experienced by the patients and with the primary stability of the mini-implants in association with the IT during placement.

\section{References}

1. Motoyoshi M, Yano S, Tsuruoka T, et al. Biomechanical effect of abutment on stability of orthodontic mini-implant: a finite element analysis. Clin Oral Implants Res 2005;16(4):480-485.

2. Saeed K, Nadim M, Morcos S, et al. In vitro assessment of maximum insertion and removal torque with three different miniscrews on artificial maxilla and mandible. J World Fed Orthod 2017;6(3): 115-119.

3. Tseng YC, Hsieh $\mathrm{CH}, \mathrm{Chen} \mathrm{CH}$, et al. The application of mini-implants for orthodontic anchorage. Int J Oral Maxillofac Surg 2006;35(8): 704-707.

4. Suzuki EY, Suzuki B. Placement and removal torque values of orthodontic miniscrew implants. Am J Orthod Dentofacial Orthop 2011;139(5):669-678.

5. Lim SA, Cha JY, Hwang CJ. Insertion torque of orthodontic miniscrews according to changes in shape, diameter and length. Angle Orthod 2008;78(2):234-240.

6. Baumgaertel S. Cortical bone thickness and bone depth of the posterior palatal alveolar process for mini-implant insertion in adults. Am J Orthod Dentofacial Orthop 2011;140(6):806-811.

7. Reynders RA, Ronchi L, Ladu L, et al. Insertion torque and success of orthodontic mini-implants: a systematic review. Am J Orthod Dentofacial Orthop 2012;142(5):596-614.

8. Motoyoshi M, Uchida Y, Inaba M, et al. Are assessments of damping capacity and placement torque useful in estimating root proximity of orthodontic anchor screws? Am J Orthod Dentofacial Orthop 2016;150(1):124-129.

9. Nucera R, Lo Giudice A, Bellocchio AM, et al. Bone and cortical bone thickness of mandibular buccal shelf for mini-screw insertion in adults. Angle Orthod 2017;87(5):745-751.

10. Łyczek J, Kawala B, Antoszewska-Smith J. Influence of antibiotic prophylaxis on the stability of orthodontic microimplants: a pilot randomized controlled trial. Am J Orthod Dentofacial Orthop 2018;153(5):621-631.

11. Park HS, Jeong $\mathrm{SH}$, Kwon OW. Factors affecting the clinical success of screw implants used as orthodontic anchorage. Am J Orthod Dentofacial Orthop 2006;130(1):18-25.

12. Motoyoshi M, Yoshida T, Ono A, et al. Effect of cortical bone thickness and implant placement torque on stability of orthodontic mini-implants. Int J Oral Maxillofac Implants 2007;22(5): 779-784.

13. Sivamurthy $G$, Sundari S. Stress distribution patterns at mini-implant site during retraction and intrusion-a three-dimensional finite element study. Prog Orthod 2016;17(1):4 
14. Jain RK, Kumar SP, Manjula WS. Comparison of intrusion effects on maxillary incisors among mini implant anchorage, j-hook headgear and utility arch. J Clin Diagn Res 2014;8(7):ZC21.

15. Sivakumar A, Sivakumar I, Sharan J, et al. Bimaxillary protrusion trait in the Indian population: A cephalometric study of the morphological features and treatment considerations. Orthodontic Waves 2014;73(3):95-101.

16. Farnsworth $\mathrm{D}$, Rossouw $\mathrm{PE}$, Ceen RF, et al. Cortical bone thickness at common miniscrew implant placement sites. Am J Orthod Dentofacial Orthop 2011;139(4):495-503.

17. Parinyachaiphun S, Petdachai S, Chuenchompoonut V. Considerations for placement of mandibular buccal shelf orthodontic anchoring screw in class III hyperdivergent and normodivergent subjects-a cone beam computed tomography study. Orthodontic Waves 2018;77(1):44-56.

18. Felicita AS, Chandrasekar S, Shanthasundari KK. Determination of craniofacial relation among the subethnic Indian population: a modified approach (vertical evaluation). Indian J Dent Res 2013;24(4):456.

19. Felicita AS. Quantification of intrusive/retraction force and moment generated during en-masse retraction of maxillary anterior teeth using mini-implants: a conceptual approach. Dental Press J Orthod 2017;22(5):47-55.

20. Dinesh SS, Arun AV, Sundari KS, et al. An indigenously designed apparatus for measuring orthodontic force. J Clin Diagn Res 2013;7(11):2623.

21. Tang X, Cai J, Lin B, et al. Motivation of adult female patients seeking orthodontic treatment: an application of Q-methodology. Patient Prefer Adherence 2015;9:249-256.

22. Vikram NR, Prabhakar R, Kumar SA, et al. Ball Headed mini implant. J Clin Diagn Res 2017;11(1):ZL02.

23. Katranji A, Misch K, Wang HL. Cortical bone thickness in dentate and edentulous human cadavers. J Periodontol 2007;78(5):874-878.

24. Meira TM, Tanaka OM, Ronsani MM, et al. Insertion torque, pull-out strength and cortical bone thickness in contact with orthodontic mini-implants at different insertion angles. Eur J Orthod 2013;35(6):766-771.

25. Tseng YC, Pan CY, Liu PH, et al. Resonance frequency analysis of miniscrew implant stability. J Oral Sci 2018;60(1):64-69.

26. Miyawaki S, Koyama I, Inoue M, et al. Factors associated with the stability of titanium screws placed in the posterior region for orthodontic anchorage. Am J Orthod Dentofacial Orthop 2003;124(4):373-378.

27. Schätzle $M$, Männchen $R$, Zwahlen $M$, et al. Survival and failure rates of orthodontic temporary anchorage devices: a systematic review. Clin Oral Implants Res 2009;20(12):1351-1359.
28. Wilmes B, Su YY, Drescher D. Insertion angle impact on primary stability of orthodontic mini-implants. Angle Orthod 2008;78(6): 1065-1070.

29. Ueda M, Matsuki M, Jacobsson M, et al. The relationship between insertion torque and removal torque Analyzed in fresh temporal bone. Int J Oral Maxillofac Implants 1991;6(4):442-447.

30. Tepedino M, Masedu F, Chimenti C. Comparative evaluation of insertion torque and mechanical stability for self-tapping and selfdrilling orthodontic miniscrews-an in vitro study. Head Face Med 2017;13(1):1-7.

31. Lee NK, Baek SH. Effects of the diameter and shape of orthodontic mini-implants on microdamage to the cortical bone. Am J Orthod Dentofacial Orthop 2010;138(1):8.e1-8. discussion 8-9.

32. Meredith $\mathrm{N}$. Assessment of implant stability as a prognostic determinant. Int J Prosthodont 1998;11(5):491-501.

33. Chen $\mathrm{YH}, \mathrm{Chang} \mathrm{HH}$, Chen $\mathrm{YJ}$, et al. Root contact during insertion of miniscrews for orthodontic anchorage increases the failure rate: an animal study. Clin Oral Implants Res 2008;19(1):99-106.

34. Watanabe T, Miyazawa K, Fujiwara T, et al. Insertion torque and periotest values are important factors predicting outcome after orthodontic miniscrew placement. Am J Orthod Dentofacial Orthop 2017;152(4):483-488.

35. Brinley CL, Behrents R, Kim KB, et al. Pitch and longitudinal fluting effects on the primary stability of miniscrew implants. Angle Orthod 2009;79(6):1156-1161.

36. Migliorati M, Signori A, Biavati AS. Temporary anchorage device stability: an evaluation of thread shape factor. Eur J Orthod 2012;34(5):582-586.

37. Pandian KS, Krishnan S, Kumar SA. Angular photogrammetric analysis of the soft-tissue facial profile of Indian adults. Indian J Dent Res 2018;29(2):137.

38. Brandão LB, Mucha JN. Degree of acceptance of mini-implants by patients undergoing orthodontic treatment: preliminary study. Dental Press J Orthod 2008;13(5):118-127.

39. Valieri MM, Freitas KM, Valarelli FP, et al. Comparison of topical and infiltration anesthesia for orthodontic mini-implant placement. Dental Press J Orthod 2014;19(2):76-83.

40. Kim SH, Yoon HG, Choi YS, et al. Evaluation of interdental space of the maxillary posterior area for orthodontic mini-implants with cone-beam computed tomography. Am J Orthod Dentofacial Orthop 2009;135(5):635-641.

41. Kim TW, Kim H, Lee SJ. Correction of deep overbite and gummy smile by using a mini-implant with a segmented wire in a growing class II division 2 patient. Am J Orthod Dentofacial Orthop 2006;130(5): 676-685. 